\title{
Causes and Consequences of Extra-Marital Relations in Married Women: A Case Study of Darulaman Sargodha
}

\author{
Nabeela Malik \\ Department of Sociology, University of Sargodha, Sargodha, Pakistan \\ Dr.Yasir Nawaz \\ Department of Sociology, University of Sargodha, Sargodha, Pakistan, Institute of Rural Home Economics, \\ University of Agriculture, Faisalabad, Pakistan \\ Dr. Babak Mehmood \\ Department of Sociology, University of Sargodha, Sargodha, Pakistan \\ Dr. Farah Riaz \\ Institute of Rural Home Economics, University of Agriculture, Faisalabad, Pakistan \\ Shahzad Khaver Mushtaq \\ Department of Sociology, University of Sargodha, Sargodha, Pakistan \\ Muhammad ijaz Khan \\ Department of Sociology, University of Sargodha, Sargodha, Pakistan
}

\section{Doi:10.5901/mjss.2014.v5n23p2044}

\section{Absrtact}

\begin{abstract}
The main purpose of the present research was to explore why married women Involve in extra-marital relations and elope with their boyfriends as a consequence and seek Shelter in Darulaman to get divorce and remarry. Mostly women in Darulaman faced a number of issues like family pressure.their personal liking, Fear and some other socio-psychological problems. For the present study, twenty cases were sampled from the targeted population through the purposive sampling technique and interview guide was administered by the researcher consisting of the following parts; a) Identification of respondent, b) demographic characteristics, c)Family factors, d) Relatives factors, e) Societal factors and Psychological factors f)economic factor, g)religious factors, h)impact on children. Case study method was used as a technique of data collection. Thematic analysis was done after the collection of actual data from the field. The major findings showed that women eloped with their boyfriends and joined Darulamans to get rid of forced marriage and marry a person of their choice, to get free from cruel clutches of male domination and suppression, to run away from suffocated atmosphere of in-law, to get rid of old age impotent husbands, to get more economic security, to improve standards of living and with a dream to live better living
\end{abstract}

\section{Introduction}

It is a universal phenomenon that people get involve into extra marital relations. In some societies it has frivolous nature and is controlled by strict social control and taboos and in some societies it is at its extreme form. Extramarital relations either frivolous or extreme have devastating effect on marital life resulting in separation or divorce. It is considered to be among the most significant threats to the stability of adult relationships, including marriage. For example, Betzig (1989) compared 160 cultures and found that infidelity was the single most cited cause of divorce. In Western countries, it has been estimated that between 25 and50\%of divorcees cited a spouse's infidelity as the primary cause of the divorce (Kelly \& Conley,1987). Among various threats that can jeopardize the spousal relationship, the most important one is infidelity. The discovery of a spouse's involvement in an extramarital affair is possibly one of the most stressful life events(C. Simon 
Fanand Hon K.Wong Lui)

The present research study has specifically focused only on women's involvement in extra marital relations. Infidelity in women is intolerable and unacceptable in a conservative society like Pakistan. It is considered a great sin and the doer of this sinful act has no place or acceptance in Muslim society. Infidelity is universal in all societies and in all times and in both sexes. But it is a strange fact that infidelity in females is not tolerated and in males it is considered their right in many instances. The research studies reveal that males are more likely to involve in extra-marital relations than females. One of the most consistent findings across decades of (Extra Marital Involvement (EMI) literature and diverse samples is that men are more likely to engage in EMI or have more extramarital partners than women (Atkins, Baucom, \& Jacobson,2001; Blumstein \& Schwartz, 1983; Buunk, 1980; Choi et al., 1994; Cochran, Chamlin, Beeghley, \& Fenwick,2004; Glass \& Wright, 1985; Greeley, 1994; Hunt, 1976; Janus \& Janus, 1993; R. E. Johnson, 1970; Laumann et al., 1994; Lawson \& Samson, 1988; Leigh et al., 1993; Pittman, 1989; Spanier \& Margolis, 1983; Træen \& Stigum, 1998; Treas \& Giesen, 2000; Wiederman, 1997; Wiggins \& Lederer, 1984).

In spite of this, the rate of infidelity in women is increasing with passage of time in Pakistan. The researcher has tried to explore reasons and factors behind this increasing trend in Pakistani women.

.There are several,social,cultural,psychological reasons of why they get involve in exta marital relations. This study is conducted in a shelter home(Darulaman Sargodh) Dar-ul-Aman is basically an institution that protects the women who are deprived of family support due to some reasons. Its purpose is to rehabilitate needy women either by arranging, settlement or marriages after the decision of the cases or to help in their certain life affairs. Women find peace in Dar-ulAman escaping the daily violence of their husbands or family, the last resort of Pakistani refuge in Dar-ul-Aman and wait for being able to become reintegrated in society. In Pakistan, around $80 \%$ of women suffered physical, sexual and psychological violence during their married or family life. Those women who can't live with their husbands due to any reason and demanded for divorce but are destitute then find a protection for a while inside in Dar-ul-Aman. (Eshraghi, 2006)

The expected social image and the required characteristic of a Pakistani woman is chastity, purity, obedience,having no individual existence, truthfulness and loyalty to her husband.A good woman should pass this standard. In this article it is considered Why a woman thinks of dodging her husband and goes to the extent of leaving his home for ever with a dream to marry another person of her choice who may prove a better substitute for her as a life partner. Home is the heaven for every woman and no woman feels comfortable to leave her heaven until the same place becomes a hell for her. The society deals such an attitude as deviant behavior. The expected behavior of a woman is to surrender her will, her desires, her wishes before the greater interests of males. Woman is considered an "entity "and a "commodity" who should have no will or desire of her own. And her every step should lead towards satisfying egoistic self of man and society. The focus of study in this article is this 'deviant' woman and it tried to explore the root cause of her involvement in extra-marital relation.

Researchers have mostly approached this topic from behavioral or psychological point of view.very few economic studies are conducted to examine factors influencing extramarital relations. Ray C. Fair in A Theory of Extramarital Affairs proposed a utility model that allocated a person's time among three activities- work, with spouse and for paramour. However, this model did not take into account the social class or the race of the sample. The primary motivation for the model is the idea that people like variety in their lives. 27.2 per-cent of the first-time-married working men and 22.9 percent of the first-time-married working women were having an extramarital affair at the time of the survey.

Kristen P. Mark • Erick Janssen • Robin R. Milhausen in "Infidelity in Heterosexual Couples: Demographic, Interpersonal, and Personality-Related Predictors of Extradyadic Sex"suggest that that, for both men and women, sexual personality characteristics and, for women, relationship factors are more relevant to the prediction of sexual infidelity than demographic variables such as marital status and religiosity.

In a research study "So What Did You Do Last Night? The Economics of Infidelity" by Bruce Elmslie and Edinaldo Tebaldi have contributed by the findings of this study to the economic literature on infidelity by providing insights into how economic factors may interact with biological related aspects of human behavior toward infidelity. Another relevant contribution of this study is to provide both theoretical and empirical results that support the view that women and men weigh the expected costs and benefits of infidelity differently. This study answers the question, "Why do people have affairs". People make calculations of cost and benefits and men and women do seem to be calculating the net benefits from having an affair differently.

In an interesting study "Intrapersonal, Interpersonal, and Contextual Factors in Engaging in and Responding to Extramarital Involvement" many factors are identified which contribute extra-marital relations. Age in older cohorts, higher education, religiosity, race, respondent's divorce status and family history of divorce, premarital sexual activity, Intrapersonal reasons that have been cited include curiosity and desire for variety, sensation seeking, experiential drives, 
reassurance of desirability or worth, to have fun, a need for conquest and power, combating a sense of inadequacy, escapism, exploring sexual orientation, or difficulties with intimacy (Atwood \& Seifer,1997; Ellis, 1969; Glass \& Wright, 1992; Greene, Lee, \& Lustig, 1974). Hunt (1976) Marital predisposing factors. Specific problems cited are varied and include boredom in the marriage, dissatisfaction with marital sex, a lack of support in the marriage, or marital conflict.EMI has been posited as a way to express hostility toward a spouse, exact revenge against a spouse, compensate for unmet needs in the marriage, or negotiate intimacy within a marriage. Clinical authors (e.g., Brown, 1991; Elbaum, 1981; Glass, 2003; Pittman, 1989; Reibstein \& Martin, 1993)

\section{Methods and Material}

The aim of present research was to explore causes and factors of extra marital relations in married women, who eloped with their boy friends and took refuge in Darulaman to get divorce from their husbands and marry the man of their choice.To fulfill research requirements, Darulaman Sagodha was selected.Interview schedule was used as a tool of data collection.Pre-testing was used to test the reliability of structured questionaire.Pretesting was useful in assessing validity of questionaire.Certain changes were made. Sample of 20 women was extracted by purpose sampling technique. Such women were selected who wanted divorce from their husbands for second marriage. Quantitative as well as qualitative methods are used in social research because it is based on empirical finding based upon observation and findings. This study was conducted in Darulaman..Demographic data was collected also to understand different variables. This study was basically based on in depth case studies of residents, case histories.Structured and non-structured interviews were conducted.

\section{Results and Discussions}

Most of the residents(65\%)belonged to age group $18-25.25 \%$ were in age group $25-40$.Statistics showed that mostly young women involved in such relations.

Most of the residents (65\%) were illiterate. It showed that women who were involved in such relations and who sought shelter in Darulaman were illiterate or had low level of education. only $15 \%$ of residents had attained higher secondary education.

Mostly residents were not employed.90\% residents had not done any job. Only 5\% residents were employed and $5 \%$ were still students.

Mostly residents belonged to rural areas.65\% belonged to rural areas and $35 \%$ belonged to urban areas. such skills.

$55 \%$ women had skills of sewing,stitching,embroidery and machine knitting and they could earn living by using

Most of the residents (60\%) said that they were not agreed on their first marriage Mostly told that they wanted to marry someone else. Age of the husband is an important factor for their unwillingness.25\% of them said that their husbands were impotent and were incapable of sexual relations, therefore they were attracted towards other men.40\% said that that they were willing for marriage but problems developed later on due to negative attitude of their husbands and in-laws.

Research findings revealed that 35\% residents had more than ten years of married life, $25 \%$ had less than 1 year and 1-5 years of married life each.15\% had 1-6 years of marriage.

$80 \%$ of the residents told that their marital relations with husband were unpleasant. $20 \%$ told that their relation with husband was pleasant and $10 \%$ told that it was normal relationship.

$70 \%$ of the residents told that their husband did verbal,psychological,financial and p.hysical violence on them. Most of them suffered physical violence. Frequency of the violence was continuous in many case.

Most of the residents(45\%) told that their mother in law is the most dominating person in her in-laws. $20 \%$ told that their father in law was the most dominating.15\% told that they themselves and sister in laws were dominating.

$55 \%$ told that they were not allowed to meet any one in their in-laws. They could not even meet their parents. They were not allowed to attend ceremonies or visit their relatives home and their relatives were not allowed to meet them in home. $25 \%$ told that they had complete freedom to meet any one in laws. $20 \%$ told that to some extent they were allowed to meet their relatives.

$60 \%$ told that they had mobile phones in their i-laws their husbands bought it for them home and $15 \%$ told that their boy friend bought it for them.45\% told that they had no mobile phones with them and they used their friend or neighbor's phones. All of them told that they had contact with their boyfriends on phone. When the family came to know about their contact on phone with them, mobile phones were snatched away from them and restrictions were imposed on 
using mobile phones.

$35 \%$ told that their relationship with their boy friend developed before marriage. their family knew about their relationship and their desire to marry the same person. They told that they were subjected to enforced marriage as their family came to know about it. They were advised,abused,beaten and strictly warned about the consequences. After enforced marriage, they kept contact with their boyfriends on mobile phones and they also met whenever possible. $65 \%$ told that it developed after marriage. And when her husband and family came to know about it, quarrels and disputes became routine of the day and the relationship became tenser. All of them told that they kept contact with their boyfriends after marriage through phone or meeting. Mostly meeting went on for a few minutes or an hour.55\% of them told that they had sexual relations with their boyfriends and $45 \%$ told that they had developed no sexual relation with them until they left their husband and home.80\% of them told that they had no sexual relation with their boyfriends before marriage.

When they were asked about reason of dispute with their husband, most of them told that it was their liking or preference for someone else which was the basic reason of dispute with their husbands. $40 \%$ of them told that their husband was also interested in someone else. And in some cases was not willing to marry her. Both were not willing to marry each other but were enforced by their family to do so. They never developed understanding between them.

The basic reason to come to Darulaman as told by $60 \%$ of the residents was to take divorce and marry their boyfriends. They told that violent attitude of their husband forced them to seek shelter in Darulaman.

$90 \%$ of them told that their boyfriends told them about Darulaman that it is an institution where one can seek shelter. They came here through a lawyer arranged by their boyfriends.

$80 \%$ of them told that they demanded divorce from their husbands before coming to Darulaman.Most of them refused to divorce and threatened of severe consequences if she demands so.

Residents were asked did their husbands fulfill their personal expenditures? $75 \%$ of them told that they did not do so. Their basic needs were not fulfilled.25\% of them told that their husbands' average monthly income was below Rs.5000.70\% of them told their income was between Rs.5000 to Rs.15000.only $10 \%$ had income above 25000. Mostly they were laborers or cultivated lands.155 had govt jobs.5\% did business.

$70 \%$ of them told that their boyfriends supported them financially. Most of the earned between 5000-15000 per month and had private business and govt.obs. $20 \%$ of them were laboures.5\% cultivated lands.

Residents were asked questions about their, their husband's and their boyfriends religious tendency. Most of them told that they were not much religious and mostly their husbands were also not much religious. But when they were asked questions about their boyfriend's religious tendency, they told that they were more religious than their husbands likewise their boyfriends families were also more religious than their husband's families.

Most of the residents had children. Mostly they had sons. Most of them left their children with their husbands or were willing to give even those children whom they brought to Darulaman. Their children were also not willing to live with step father. They preferred to live with their own father and leave a mother who left them. Most of the residents told that their boyfriends after marriage will not be willing to keep children from their first husbands.

\section{Conclusion}

Demographic data showed that most of the women were teenagers and were illiterate. Mostly were house wives and currently not employed. Mostly belonged to rural set up. Most of them were equipped with skills like sewing and stitching. Younger age, no education, no employment, rural background is contributing factors in making such decisions. In our social set up, marriages are arranged rather imposed in many cases. Most of the women were not agreed for marriage due to age and poverty of husband and the most important is their preference for someone else for marriage. They were subjected to forced marriage which they never fully compromised. Moreover their husband's attitude was negative; most of them suffered physical, verbal, psychological violence. Women had unpleasant relationship with their in-laws. Mother in law was dominating person who imposed restrictions including not freely allowed to meet even family and relatives. They were not allowed to keep mobile phones. To get rid of this suffocation was an important factor in their decision making. It was interesting to note that most of them had lived with their husbands for more than ten years. Mostly had more than 2 children. After such a long period, they made this critical decision.

All of them had contact with their boyfriends on mobile phones. Most of them developed relationship after marriage and had sexual relations with them. Mostly told that that they had no sexual relation with them before marriage..When their husbands came to know about it, their attitude became harsher and they were physically beaten and imposed restrictions. They first felt ashamed and later resented and became rebellions.

The basic reason to get divorce from husband was to merry person of their choice. Physical violence and poverty was another important contributing factor. Research findings showed that their boyfriends were more economically sound 
than their husbands and supported them financially when they were with their husbands.

The research study also revealed that these women were not much religious minded and their husbands also had less religious tendency. They told that boyfriends were more religious than their husbands.

Most of the women had more than 2 children and mostly did not bring them to Darulaman. They said that they don't want to keep children with them after second marriage because their boyfriends are not willing for this, nor the children want to live with them.

In short, married women run away with their boyfriends because of many socio-psychological, economic and religious factors. Enforced marriage, spousal abuse, age, impotency of husband, ,poverty of the husband, no understanding, verbal,psychological,physical violence, male domination and suppression, better economic well being of boy friend, emotional attachment with boy friend are the basic factors for involving in extra-marital relations and consequently their decision to get divorce from their husbands and opt for second marriage.

\section{References}

Atkins, D. C., Yi, J., Baucom, D. H., \& Christensen, A.(in press). Infidelity in couples seeking marital therapy.Journal of Family Psychology.

Azam Samina, Zahra Saddaf , Zainab Kanza, Sunny Rabia:" Causative Factors Pushed Women Into Dar-ul-Aman: A Case Study Of Dar-ul-Aman District Gujrat, Pakistan" Vol.4 No.3, Academic Research International

Betzig, L. (1989). Causes of conjugal dissolution: A crosscultural study. Current Anthropology, 30, 654-676.

Chernozhukov, Victor, and Hong, Han. 2002. "Three-Step Censored Quantile Regression and Extramarital Affairs." Journal of the American Statistical Association 97, no. 459.

Elmslie, Bruce, and Tebaldi, E. 2008. "So, What Did You Do Last Night? The economics of infidelity." Kyklos 61, no. 3: 391-410. EconLit, EBSCOhost (accessed November 24, 2010).

Fair, Ray C. 1978. "A Theory of Extramarital Affairs." Journal of Political Economy 86, no. 1: 45-61. EconLit, EBSCOhost (accessed November 23, 2010).

Fan, C. Simon, and Hon-Kwong Lui. 2004. "Extramarital Affairs, Marital Satisfaction, and Divorce: Evidence from Hong Kong." Contemporary Economic Policy 22, no. 4: 442-452. EconLit, EBSCOhost (accessed November 25, 2010).

Kelly, E. L., \& Conley, J. J. (1987). Personality and compatibility: A prospective analysis of marital stability and marital satisfaction. Journal of Personality and Social Psychology, 52, 2740.

Kristen P. Mark • Erick Janssen • Robin R. Milhausen,2011 "Infidelity in Heterosexual Couples: Demographic, Interpersonal, and Personality-Related Predictors of Extradyadic Sex"

Liu, Xuemei. 2008. "An Effective Punishment Scheme to Reduce Extramarital Affairs: An Economic Approach." European Journal of Law and Economics 25, no. 2: 167-175. EconLit, EBSCOhost (accessed October 5, 2011). 